\title{
Cooperative Family Registry
}

National Cancer Institute

\section{Source}

National Cancer Institute. Cooperative Family Registry. NCI Thesaurus. Code C15938.

A comprehensive, collaborative infrastructure, linked to an informatics structure, to help speed the genetic and epidemiologic study of heritable cancers. Twelve participating institutions are located in the United States, Canada, and Australia. 